\title{
ESTRATÉGIAS DE DIÁLOGO COM O ESTRANHAMENTO NO COMEÇO DA VIDA UNIVERSITÁRIA POĹTICAS DE ACOLHIMENTO E PERMANÊNCIA NA UNIVERSIDADE FEDERAL DO SUL DA BAHIA
}

\author{
DIALOGUE STRATEGIES WITH ESTRANGEMENT IN THE BEGINNING OF UNIVERSITY \\ LIFE HOME AND PERMANENCE POLICIES AT THE FEDERAL UNIVERSITY OF \\ SOUTHERN BAHIA \\ ESTRATEGIAS DE DIÁLOGO CON EL EXTRANJAMIENTO EN EL COMIENZO DE LA VIDA \\ UNIVERSITARIA POLÍTICAS DE ACOGIDA Y PERMANENCIA EN LA UNIVERSIDAD \\ FEDERAL DEL SUR DE BAHÍA
}

\section{Sandro Augusto Silva Ferreira'}

RESUMO: As transformações recentes na Universidade Pública, especialmente quanto as políticas de ingresso por meio das Ações Afirmativas, geram um conjunto de desafios na promoção da permanência material e simbólica na universidade. Além dos programas de assistência estudantil voltadas ao apoio pecuniário, tem se tornado necessário um conjunto de novas intervenções voltadas ao acolhimento e produção de afiliação aos novos estudantes, na sua maioria oriundos de famílias sem histórico de formação universitária. Neste sentido as atividades de recepção e orientação nos primeiros dias, e as ações de combate ao trote e outras violências assume importante papel na construção de trajetórias de sucesso na universidade. Este artigo avalia, por meio de um relato de experiência, o modelo adotado pela Universidade Federal do Sul da Bahia na recepção aos alunos da sua segunda turma. Avalia também a potencialidade deste mecanismo de afiliação para o sucesso dos diversos programas de ações afirmativas.

PALAVRAS-CHAVE: Ações afirmativas. Semana de acolhimento. Calouro.

\begin{abstract}
Recent changes in the Public University, especially as the admission policies through Affirmative Action, generate a set of challenges in promoting material and symbolic stay at the university. In addition to student assistance programs aimed at monetary support has a new set of interventions aimed at the reception and production of affiliation become necessary for new students, mostly from families with no history of university education. In this sense the reception activities and guidance in the early days, and Deeds to combat hazing and other violence plays an important role in building successful careers in college. This article evaluates, by means of an experience report, the model adopted by the Federal University of Southern Bahia at home to students of their second class. It also assesses the potential of this affiliation mechanism for the success of the various affirmative action programs.
\end{abstract}

KEYWORDS: Affirmative action. Welcome week. Freshman.

RESUMEN: Las transformaciones recientes en la Universidad Pública, especialmente en cuanto a las políticas de ingreso a través de las Acciones Afirmativas, generan un conjunto de desafíos en la promoción de la permanencia material y simbólica en la universidad. Además de los programas de asistencia estudiantil orientados al apoyo pecuniario, se ha vuelto necesario un conjunto de nuevas intervenciones dirigidas a la acogida y producción de afiliación a los nuevos estudiantes, en su mayoría oriundos de familias sin antecedentes de formación universitaria. En este sentido las actividades de recepción y orientación en los primeros días, y las acciones de combate al trote y otras violencias asume un papel importante en la construcción de trayectorias de éxito en la universidad. Este artículo evalúa, por medio de un relato de experiência, el modelo adoptado por la

Submetido em: 15/05/2017 - Aceito em: 21/06/2017 - Publicado em: 04/07/2017.

v.3

n. 2


Universidad Federal del Sur de Bahía en la recepción a los alumnos de su segunda clase. También evalúa la potencialidad de este mecanismo de afiliación para el éxito de los diversos programas de acciones afirmativas.

PAlABRAS ClAVE: Acciones afirmativas. Semana de acogida. Calabozo.

\section{INTRODUÇÃ̃O}

O debate acadêmico e político sobre a educação no Brasil é cada dia mais destacado. A persistência de diversos problemas, assim como os pontuais avanços conquistados, sobretudo no que tange ao último ciclo de expansão do ensino superior público, tem estimulado diversas pesquisas. Não são poucos os estudos que identificam as características desta expansão, e a sua importância estratégica para o desenvolvimento econômico e social do nosso país. Porém, falta atenção nestes estudos quanto aos significados simbólicos deste processo na vida de contingentes expressivos da população, que sequer sabia o que era uma universidade.

Atento a esta lacuna, este estudo analisa, por meio do relato da experiência de realização da Semana de Acolhimento - Recepção "Calourosa", ocorrida em maio de 2015 na Universidade Federal do Sul da Bahia, as possibilidades de construção de mecanismos de afiliação dos novos estudantes ingressantes nas universidades após a promulgação da Lei de cotas, 12.711/2012 e dos diversos programas de Ação Afirmativa, sobretudo nas universidades públicas. Considerando o perfil destes novos estudantes, oriundos de setores populares e minorias sociais, o estudo analisa também a importância de mecanismos de orientação acadêmica e de combate ao fenômeno do trote universitário, na produção de afiliação à universidade e de redução dos índices de evasão e ociosidade de vagas no ensino superior.

O último ciclo de expansão do ensino superior, em especial por conta da sua interiorização, criou a possibilidade de que novos segmentos sociais, alguns flertando com a marginalidade ${ }^{2}$ socioeconômica, pudessem visualizar uma chance de entrar em uma universidade. Ainda que caiba uma análise crítica sobre os tortuosos caminhos para o sucesso acadêmico desta entrada - muito por conta da dificuldade de parte dessas universidades visualizarem nesta expansão a possibilidade de uma mudança em seus modelos curriculares e pedagógicos - é preciso ressaltar o quanto esta presença mais facilitada de um curso universitário (muitas vezes bem ao lado) cria processos de motivação e de reforço de autoestima nestes grupos sociais.

A associação desta expansão com as políticas de ações afirmativas, em especial a reserva de vagas para alunos oriundos de escola pública, abre a universidade para um tipo novo de estudante universitário. Segundo Bergmann (1996 apud MOEHLECKE, 2002, p. 199), a tarefa central da "ação afirmativa é planejar e atuar no sentido de promover a representação de certos tipos de pessoas - aquelas pertencentes a grupos que têm sido subordinados ou

\footnotetext{
${ }^{2}$ Aqui pensada em seu sentido sociológico.

\begin{tabular}{|l|l|l|l|l|l|} 
Rev. Inter. Educ. Sup. & Campinas, SP & v.3 & n.2 & 291-307 & maio/ago. 2017
\end{tabular}
}


excluídos - em determinados empregos ou escolas”.

Além de sua origem social, poucas caracterizações demográficas são possíveis. São tanto jovens, quanto maduros, homens e mulheres, com uma crescente vantagem estatística destas, nas duas últimas décadas. Enfim, se trata de um contingente variado de pessoas que agora acessam a universidade pública.

Mas a chegada à porta da universidade não significa necessariamente um passo seguro para o lado de dentro. Muitos bloqueios, de um lado, e muitas tradições, do outro, interferem nessa decisão de frequentar um curso universitário. Muitas outras razões, de caráter objetivo, se impõem como responsáveis mais evidentes da baixa ocupação das vagas (muitos estudos já apontam a tendência a uma relativa ociosidade de vagas desta última expansão) e pelos ainda altos índices de evasão e insucesso (trancamentos de matrícula por períodos longos, abandono da vaga, desligamento da instituição, etc.).

Os dados do Censo da Educação Superior (2015), indicam a matrícula de 8.027.297 estudantes no ensino superior, um aumento de 2,5\% em relação a 2014. Os dados também apontam que das 6,1 milhões de novas vagas em instituições públicas e privadas de ensino superior, somente $42,1 \%$ foram ocupadas, e das vagas remanescentes deste período, apenas 13,5\% foram reaproveitadas. Em 2015 o número de matrículas trancadas (1.300.410) e de matrículas desvinculadas (1.735.546), também apresentadas pelo Censo da Educação Superior, apontam um peso proporcional significativo de situações que podem (na maioria dos casos) ser consideradas como evasão.

Mesmo diante destes dados, consideramos que o ENEM/SISU (Exame Nacional do Ensino Médio/Sistema de Seleção Unificado), organizado pelo MEC - Ministério da Educação, se tornou uma opção seletiva que inegavelmente democratizou a possibilidade de concorrer a uma vaga do ensino superior público. Ela colabora inclusive para uma mobilidade espacial de estudantes jamais vista, em especial nas famílias pobres brasileiras. Hoje já não é mais incomum um estudante do Nordeste ser selecionado para uma vaga numa universidade do Sul/Sudeste, e vice-versa. Segundo dados divulgados pelo MEC em 2013, avaliando os deslocamentos de estado de origem na matrícula de alunos aprovados no SISU daquele ano, de 5.809 estudantes baianos matriculados nas IES pelo SISU/2013, 1058, 18,21\%, o fizeram em instituições fora da Bahia, taxa bem superior a nacional que fica próximo de $13 \%$. 


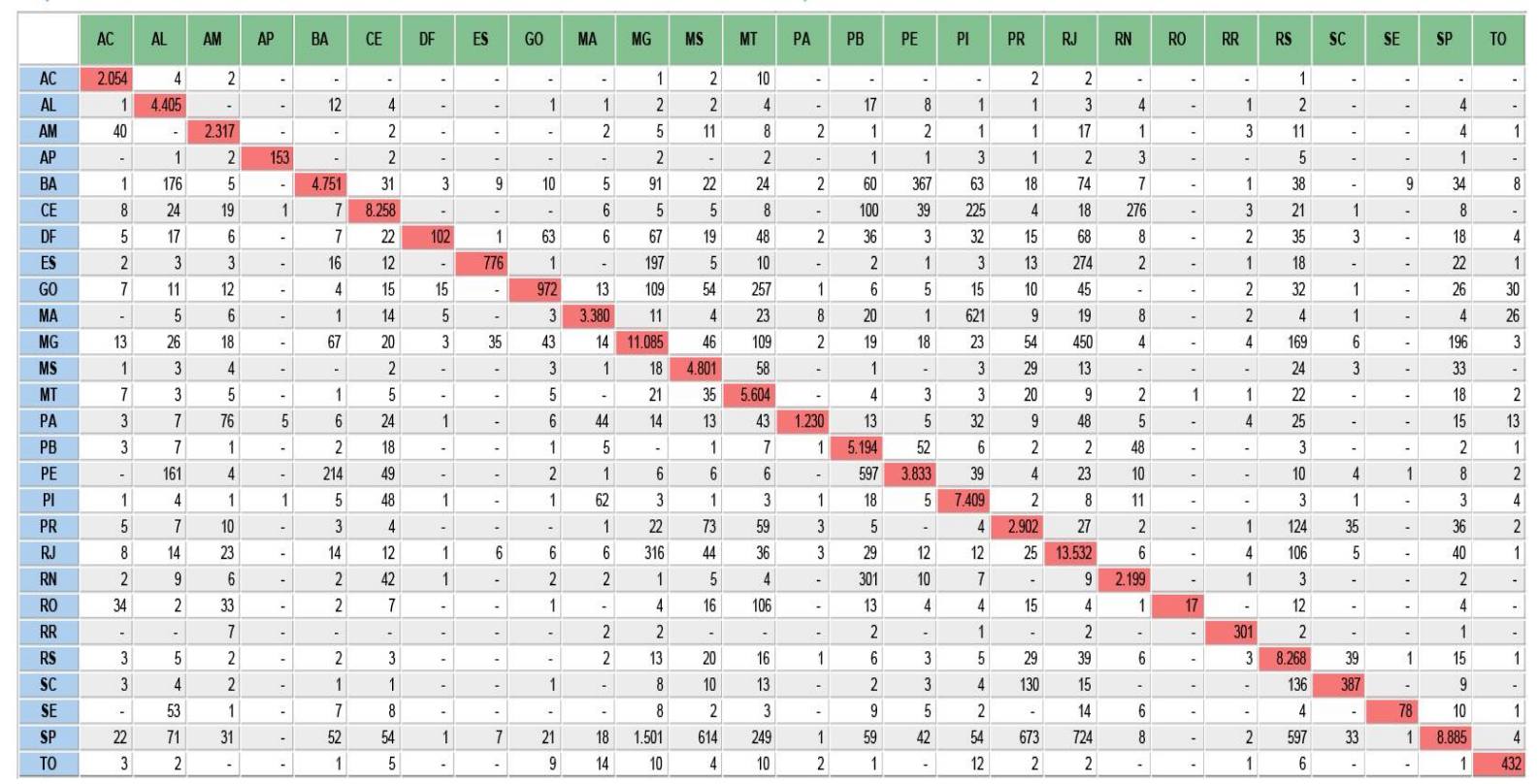

Gráfico 1. Deslocamentos dos Estudantes Matriculados no SISU/2013

Fonte: Ministério da Educação, 2013.

A questão é que, entre optar pela vaga desta universidade distante e estar presente na sua primeira aula, existe um grande hiato. No caso da UFSB - Universidade Federal do Sul da Bahia, este hiato é ainda mais longo, já que, por conta do seu regime quadrimestral, a seleção do aluno é feita entre janeiro e fevereiro, mas o seu ingresso efetivo só ocorre no segundo quadrimestre, a partir de maio. A redução deste hiato pode ser realizada por meio da Assistência Estudantil, aqui pensada como um instrumento essencial para o sucesso das Ações Afirmativas.

A adesão à Lei de Cotas, $n^{\circ}$ 12.711/2012, possibilita identificar, ainda na matrícula, quantos e quais são estes alunos que encontrarão possíveis dificuldades objetivas para efetivar a opção de universidade feita no SISU. As reservas de algo em torno de $30 \%$ das vagas para estudantes com comprovada renda per capita bruta familiar de até 1,5 salários mínimos (L1 e L2) permite identificar os estudantes que potencialmente demandarão apoio para os custos relacionados a vida acadêmica, em especial de transporte, alimentação e moradia. Este último, a necessidade de morar na cidade onde irá realizar os seus estudos, é sem dúvida o maior dos dramas. Ainda que muitos busquem a possibilidade de contar com a solidariedade de amigos e familiares, a grande maioria precisa desembolsar valores significativos para aluguel e todos os gastos relacionados. Esta dificuldade se configura numa das principais causas da não ocupação real de vagas.

Muitas dessas novas universidades, apesar de contar com o suporte do PNAES - Programa Nacional de Assistência Estudantil, não contam com residências e restaurantes universitários e, mesmo com a concessão de bolsas/auxílios moradia, encontram dificuldades de divulgar, 
potencializar e acelerar a sua concessão a estes alunos oriundos de áreas distantes. Ações como a concessão de auxílios para a instalação, concedidos de forma emergencial, ou até mesmo a construção de uma rede de contato e informação com estes alunos neste período, podem ser decisivas na hora de definir a ida ou não para a cidade onde o estudante irá estudar.

Considerando estas questões, o sucesso das políticas de expansão de vagas, em especial em relação aos estudantes oriundos de famílias socialmente vulneráveis, não pode ser pensado de forma desassociada das políticas de permanência, em seu sentido amplo. A concessão de auxílio pecuniário a estes estudantes é uma destas políticas, e precisa estar associada a outras ações de caráter político, pedagógico e cultural, que venham a ampliar a concepção restrita vigente de assistência estudantil. Uma observação mais detalhada dos dados sobre evasão demonstrará que este fenômeno não ocorre apenas entre os estudantes em condição de vulnerabilidade social, ainda que sobre estes os impactos sejam mais significativos.

\begin{abstract}
O crescimento da demanda social por formação superior e das possibilidades de acolhimento, as diversas reformas que foram realizadas ao longo dos últimos vinte anos não resultaram numa mudança sensível das taxas de fracasso e abandono observadas. Para compreender este fenômeno, é necessário abrir a 'caixa preta' da seleção na universidade e tentar ver, pela prática de uma etnografia de campo, como se fracassa, quais são os mecanismos e as conexões internas desse processo de seleção e de classificação social que distingue aquele que permanecerão estudantes daqueles que serão excluídos. (COULON, 2008, p. 31)
\end{abstract}

Quais seriam então os fatores que incidem de maneira mais horizontal (ou com oscilações menores) no processo de abandono precoce dos estudantes que ingressam na universidade? Qual é o momento mais crítico para a fixação do estudante numa universidade?

\title{
ESTRANHAMENTO E AFILIAÇÃO
}

Os estudos de Alain Coulon, em especial sua obra "A condição de Estudante: a entrada na vida universitária" (2008), assumem importante papel nas análises recentes sobre expansão, permanência e assistência estudantil na Bahia. O conceito de estranhamento aplicado à compreensão da transição do ensino médio para o ensino superior nos ajuda na percepção dos diversos fatores materiais e culturais que tornam a vida universitária uma fase especial e ao mesmo tempo complexa. A estreita relação contemporânea entre formação universitária e sucesso profissional e financeiro coloca a universidade num lugar de destaque e no objetivo fundamental para a vida de jovens (e não jovens), e agora, inclusive, de jovens oriundos de famílias pobres.

Coulon (2008) destaca o primeiro ano como o mais crítico (catastrófico para alguns inclusive) na adaptação e permanência no ensino superior.

Esse conjunto de reflexões me levou a pensar que, se o primeiro ano de

\begin{tabular}{|l|l|l|l|l|l|} 
Rev. Inter. Educ. Sup. & Campinas, SP & v.3 & n.2 & 291-307 & maio/ago. 2017 \\
\hline
\end{tabular}


universidade é tão catastrófico para muitos e tão difícil para todos, era porque, além da capacidade e da aptidão de cada um, existiam problemas sérios de adaptação ao ensino superior. Os estudantes que aí chegam, vindo diretamente do ensino médio, ficam geralmente surpresos de ter tanta dificuldade para se adaptar a esse novo quadro que é a universidade. (idem, p. 36)

O que pretendo com este estudo é ampliar o zoom neste primeiro ano em direção à primeira semana, aos momentos introdutórios dos rituais da universidade, onde novas tradições se impõem e, para muitos desses estudantes sem antecedentes familiares neste ambiente, até agridem seus conceitos de normalidade e sociabilidade. A universidade precisa se responsabilizar por estes elementos estruturais e simbólicos que incidem sobre a construção da identidade de estudante, caminhando para a transformação, e mesmo o combate à estas práticas que dificultam uma transição mais tranquila e que colabore para a afiliação.

Parte das principais dificuldades para a constituição da identidade de estudante está relacionada à precariedade da própria universidade na integração destes indivíduos em seu espaço. $\mathrm{O}$ entendimento dos percursos do processo de afiliação, aqui entendida como " $O$ método através do qual alguém adquire um status social novo" (idem, 2008, p.32), possibilita à universidade criar mecanismos que fortalecem, no antigo "aluno", a constituição da condição de "estudante".

O entendimento sobre quem é este estudante, ainda no primeiro ano de universidade, só é possível através do entendimento dos processos de socialização ocorridos simultaneamente na família e na sociedade. Estes dois grupos influenciam, os então alunos, a escolherem ainda muito cedo os cursos que os transformarão em trabalhadores, e as funções que exercerão pelo resto da vida. Por conta disso, há uma enorme pressão para que optem pelas melhores instituições de ensino superior.

Coulon (2008) trata essa transição do ensino médio para o ensino superior como delicada, e responsável pelos maiores índices de fracasso ao longo do primeiro ciclo. Três especificidades do ensino superior tornam este primeiro momento ainda mais tenso: Primeiro, o ensino superior se dirige a adultos e, portanto, exige autonomia que muitos ainda não conquistaram. Segundo, ele é terminal, e em tese te prepara para a vida ativa (profissional). E, terceiro, a entrada no ensino superior é voluntária, e o seu abandono não se constitui num "crime", o que certamente torna mais fácil a "opção" pelo abandono. Se considerarmos o quadro atual de relativa facilidade e redução de custos (taxas de inscrição e matrícula, deslocamento para realização de provas, etc.) para o acesso a uma vaga na universidade, a opção pelo abandono se amplia, assumindo, muitas das vezes, um caráter de intervalo simples, entre uma tentativa e outra.

Esta ponte entre o ensino médio e o ensino superior é denominada por Coulon (2008) como

n.2


"processos de passagem". Ele elenca três fases desta transição à condição de estudante. São elas: o tempo de estranhamento, onde ocorre a separação em relação ao status passado; o tempo de aprendizagem, que se constitui numa fase de constantes ambiguidades, e o tempo de afiliação, fase de conversão, admissão no ambiente acadêmico.

O autor destaca que o status social de estudante tende a ser provisório, e que internamente a universidade há uma seleção social, que faria emergir/excluir os que irão ou não permanecer. "Os estudantes que aí chegam, vindo diretamente do ensino médio, ficam, geralmente, surpresos de ter tanta dificuldade para se adaptar a esse novo quadro que é a universidade." (idem, 2008, p.36)

A entrada na vida universitária compreende muito mais que somente ser aprovado no vestibular/ENEM, é preciso passar pelos rituais iniciais, aprender a se misturar, aprender a encurtar os caminhos burocráticos, ultrapassar as barreiras do anonimato ou se acostumar a ser apenas mais um.

Estes dramas estão muito relacionados ao momento em que o estudante já optou por iniciar o curso, se dispondo a enfrentar a dinâmica (nova) dos primeiros meses. É necessário pensar um pouco antes, considerar também como decisivos (e antecedentes) os momentos que vão do resultado do processo seletivo à primeira semana de aula. Que angústias e expectativas interferem na construção da condição de estudante nesse período? Que práticas e tradições da universidade podem acolher, ou mesmo, excluir este potencial estudante?

\section{TROTE, VIOLÊNCIA INSTITUCIONAL E RITOS DE PASSAGEM}

É cada vez mais comum a produção de eventos de recepção aos novos alunos (calouros, bichos, feras, etc.) nas universidades. Estas se apresentam tanto como ações institucionais, quanto como ações externas, produzidas pelos próprios estudantes, algumas com a evidente intenção de lucrar com o simbolismo da chegada à universidade.

A UFSB, em sua curta história, vem dando atenção destacada a estes momentos introdutórios, realizando atividades de recepção e aulas inaugurais. Estas atividades assumem papel ampliado, para além de um simples rito de passagem, tornando-se também um momento de consolidação e publicidade dos seus princípios e valores expressos em sua Carta de Fundação e Plano Orientador.

Humanismo - na medida em que as atividades de ensino, pesquisa e extensão consideram o ser humano em todas as suas dimensões (afetiva, cognitiva, espiritual, econômica, social, ambiental), procurando formar pessoas atuantes e cientes do seu papel enquanto cidadãos, produtores de bens e serviços, consumidores conscientes, partícipes da sociedade e da natureza. (UNIVERSIDADE FEDERAL DO SUL DA BAHIA, 2014, p, 19)

n. 2

291-307


Cabe destacar que as características pedagógicas e o grau de inovação do nosso modelo ampliam as possibilidades de estranhamento destes novos alunos. $\mathrm{O}$ regime quadrimestral, a progressão em ciclos, e a aprendizagem interdisciplinar são algumas destas características que demandam amplo esclarecimento e produção de adesões entre os novos estudantes.

Somado a isso, a UFSB assumiu a tarefa de combater todas as formas de trotes, mesmo que estes possam ser considerados "não violentos" ou "solidários", partindo do pressuposto de que qualquer ação baseada em constrangimento é produtora de angústias e, até mesmo, desistências entre nossos alunos.

A iniciação universitária era uma tradição medieval. Nasceu quando as universidades eram poucas e reservadas à elite nobre, que se considerava uma casta superior com ascendência divina. (...) O trote compreendia rituais de humilhação e submissão impostos aos candidatos a alumni. Havia também provas de sofrimento e coragem, muitas vezes custando vidas humanas. (ALMEIDA FILHO, 2007, p. 142).

É sempre bom destacar o quão enorme são as dificuldades encontradas na tentativa de dialogar com essa prática. A linha entre uma bela iniciativa de "obrigar" a doação de sangue (Trote solidário) e a tortura física que, por muitas vezes (muitas mesmo), já resultaram em morte, é muito tênue. A UFSB optou em proibir radicalmente qualquer tipo de trote, registrando isso nos documentos formais da universidade e no Código de Ética Estudantil, que foi exaustivamente apresentado aos estudantes na primeira semana de aula da primeira turma em setembro de 2014, voltando a ser debatido com a segunda turma, ingressante em 2015.2 .

Art. $7^{\circ} \mathrm{O} / \mathrm{A}$ ESTUDANTE é corresponsável pelo respeito às singularidades e especificidades culturais, sociais, artísticas e econômicas de indivíduos, colegas, professores e funcionários, visando ao convívio harmônico e não discriminatório com diversidades étnicas, raciais, estéticas, de origem, de identidade de gênero e de orientações sexuais, tratando a todos com alegria e civilidade.

(...)

Art. $12^{\circ}$ São condutas vedadas ao/a ESTUDANTE:

I. promover, realizar ou participar de qualquer tipo de trote ou atividade similar;

II. utilizar qualquer forma de violência física, verbal, psicológica ou moral em qualquer atividade dentro e fora da UNIVERSIDADE;

III. motivar, incentivar e/ou participar de situações que possam gerar humilhação, constrangimento ou qualquer forma de violação à dignidade da pessoa humana; IV. participar direta ou indiretamente de ato discriminatório contra qualquer membro da comunidade acadêmica e transacadêmica;

(Código de Ética Estudantil da UFSB ${ }^{3}$ )

\footnotetext{
${ }^{3}$ Código de Ética Estudantil. Disponível em: http://www.ufsb.edu.br/content/c\%C3\%B3digo-de-\%C3\%A9ticaestudantil 
Ainda há um longo caminho para avaliarmos se medidas mais duras como estas surtirão efeito, porém esta ação aponta um caminho necessário, diante da incapacidade institucional de gestores, assim como de professores e alunos veteranos, em lidar com esta prática violenta disfarçada de tradição.

Ao ingressarem na Universidade, os calouros, pensam que vão ter que se esforçar para conseguir a graduação, mas não pensam, ou pelo menos não pensavam até virar algo corriqueiro no meio acadêmico, que a vida na Universidade seria iniciada com uma prática tida por muitos como "tradição", como "brincadeira", que na verdade é algo perverso, uma prática que veste o manto do ignóbil bullying: o Trote Universitário. (VIEIRA SEGUNDO, 2013, p, 01)

Associado as medidas jurídicas adotadas (códigos de ética, interdições e proibições em geral, etc.), outras ações de integração e conscientização contra o trote foram adotadas por diversas universidades. Campanhas visuais, com cartazes e mídias diversas, são as mais comuns. A UFSB em 2015 publicou uma campanha que busca associar o trote a outros tipos de violência, reforçando a crítica social com o destaque as legislações que proíbem e punem sua prática.

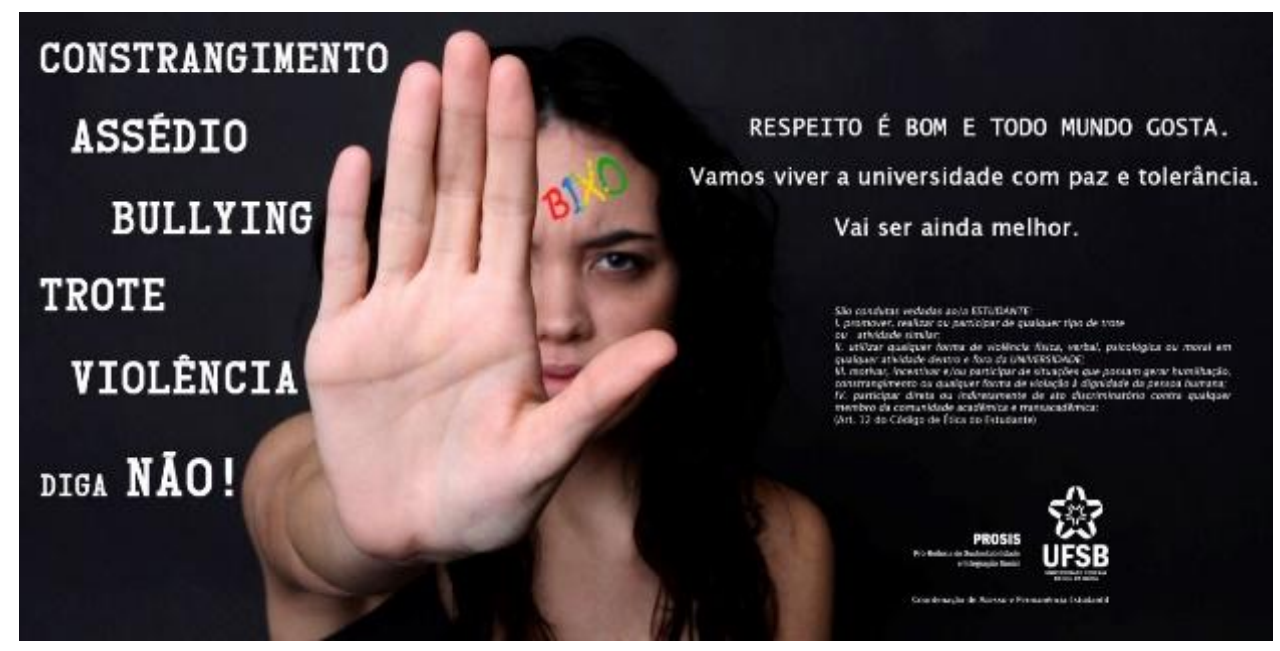

Figura1. Cartaz da Campanha de combate ao Trote da UFSB em 2015

Fonte: Site da UFSB

Até o momento o que pudemos verificar foi uma razoável adesão aos princípios da campanha por parte dos calouros, e também dos veteranos, com raras exceções expressas nas redes sociais. Nenhum ato associado a trote foi verificado após a realização das atividades de acolhimento, da campanha visual e da divulgação do Código de Ética Estudantil e da Comissão de Ética Estudantil ${ }^{4}$.

\footnotetext{
${ }^{4}$ A CODE - Comissão de Ética Estudantil - é eleita através de votação direta de todo o corpo acadêmico, que escolhe representantes das três categoriais para a sua composição. Estão entre as principais atribuições da CODE, descritas no Art. 14 do Código de Ética Estudantil: "I - promover a educação da comunidade da Rev. Inter. Educ. Sup. Campinas, SP \begin{tabular}{l|l} 
v.3 & n.2
\end{tabular} 291-307 maio/ago. 2017
} 
Mesmo com a divulgação ampla realizada com a primeira turma dos princípios estabelecidos no Código de Ética Estudantil, a UFSB registrou alguns casos de constrangimento/assédio ocorridos especialmente através das redes sociais. Como vem se tornando característico nas universidades, a UFSB também tem apoiado o uso de tecnologias de aprendizagens e de comunicação constante através das redes sociais. E, nestes espaços, tem se registrado episódios diversos que vão desde discussões mais exasperadas a situações claras de assédio, típicas daquilo que vem sendo chamado recentemente de cyberbulliyng.

O ciberbullying, talvez a mais cruel das práticas do bullying por se espalhar rapidamente e muitas vezes serem praticadas por meio do anonimato, é uma das novidades que, com o advento da tecnologia, transformou os momentos de tortura e humilhação, que antes acometia as vítimas somente entre os muros escolares, em martírios infinitos, numa propagação de divulgação bem maior do que se poderia imaginar. Antigamente, com o término das aulas, o sofrimento das vítimas obtinha tréguas. Hoje, com as humilhações ocorrendo em redes sociais acaba acompanhando as vítimas em todo canto e em qualquer horário. (NASCIMENTO, 2014)

Não estranhamente, na maioria das vezes, estes episódios ocorrem justamente contra jovens estudantes mulheres. Ainda que exista uma tendência em considerar o Trote, ou as diversas formas de violência associadas a este, como um fenômeno horizontal quanto ao gênero, não há como negar que os registros mais recentes demonstram a maior incidência, ou um recorte sexista/androcêntrico, sobre as mulheres. As consequências também são diversas já que,

\begin{abstract}
... muitas vezes internalizando os sentimentos negativos gerados pela rejeição, as meninas passam a agir de maneira solitária, tímida e insegura, tornando-se, assim, campos atrativos para aproximar distúrbios como bulimia, anorexia, automutilação ou depressão. Já os meninos costumam encarar o sofrimento como brincadeira, "zoação", em uma espécie de "rito de passagem" para o amadurecimento. Os que não apresentam essa visão, por vezes, desenvolvem desejo de revide, de vingança, de equiparação de sofrimento. (NASCIMENTO, 2014, p. 95)
\end{abstract}

O desenvolvimento de estudos sobre as dinâmicas identitárias no ambiente universitário tem dado pouca atenção ao papel deste fenômeno em específico, o trote, para a construção das trajetórias e identidades dos estudantes quanto ao gênero e a sexualidade. As expectativas criadas pelos veteranos sobre a participação dos calouros nestes rituais de iniciação à vida universitária quase sempre se baseiam em posturas de gênero que reificam as representações sexistas de papéis, que sem dúvida se imporão sobre a construção das autoimagens e representações sociais dos alunos no decorrer de sua trajetória universitária.

Universidade Federal do Sul da Bahia, mediante a ampla divulgação deste Código de Ética; (...) III - tomar conhecimento de denúncias e representações formuladas por integrantes do corpo discente da UNIVERSIDADE, pertinentes às normas dispostas neste Código e demais dispositivos normativos da vida universitária; 
Podemos entender os trotes universitários como "tecnologias do eu" no sentido foucaultiano, na medida em que envolvem práticas e representações em que os indivíduos expressam uma certa "verdade" sobre si e sua sexualidade, de modo a se tornarem homens e mulheres de um dado tipo. (SIQUEIRA e ROCHA, 2008, p. 02)

Deste modo, torna-se importante a atenção institucional a este momento de entrada na universidade, e também no decorrer das trajetórias destes estudantes em seu complexo processo de afiliação. Os atos normativos de combate aos atos de violência são importantes, mas são necessárias também outras intervenções que libertem a construção das identidades individuais e coletivas dos estudantes dentro da universidade, tornando efetiva a produção de cidadanias plenas e críticas, que tanto falamos em nossos planos orientadores e pedagógicos. Intervenções que garantam ao máximo o direito a diversidade (a exemplo da criação de resoluções de uso acadêmico do nome social), o direito a construção de suas próprias trajetórias formativas (através da flexibilização curricular) e o direito ao acolhimento e acompanhamento de sua vida acadêmica.

Uma ação, já presente em algumas instituições, também desenvolvido na UFSB, é a Atividade de Orientação Acadêmica, atividade complementar obrigatória aos estudantes calouros, que cumpre importante papel para o acolhimento inicial e para a afiliação e a orientação institucional aos estudantes. Através da composição de equipes de aprendizagem, orientadas por uma dupla de docentes de formações profissionais distintas, os estudantes encontram a possibilidade de compreender melhor os caminhos formais da universidade e de constituir laços de amizade e de produção de conhecimento entre seus pares.

A Atividade de Orientação Acadêmica (AOA) tem como objetivos: a) acolher o
discente na Universidade e ajudá-lo a superar a fase de estranhamento,
acompanhando-o ao longo do primeiro ano de modo a promover a sua afiliação
acadêmica; b) orientar o discente para uma transição tranquila e organizada do
Ensino Médio para o Superior, favorecendo a sua integração no ambiente
universitário. (MANUAL...2004, p.2)

Cabe ressaltar que a opção pela ação preventiva, visando evitar qualquer possibilidade de que atos realizados por estudantes evoluam para qualquer modalidade de trote, está claramente associada aos objetivos pedagógicos de uma universidade. Em especial, quando estas consideram que atos de constrangimento em nada colaboram para o bom desenvolvimento intelectual dos estudantes e para a redução das elevadas taxas de evasão verificadas no ensino superior.

A confirmação e a consolidação no calendário regular universitário de ações de acolhimento e combate ao trote criam espaços de diálogo e afiliação processual dos novos alunos, possibilitando também a constituição de um canal anual institucional de integração com a comunidade (alunas/os, mães, vizinhas/os, etc.) dando visibilidade a sua presença, papel e ações na região onde se instala. 
A chegada à universidade é uma confrontação progressiva com práticas novas. A chegada na universidade é a descoberta de outro mundo, no qual, antes de qualquer coisa, é preciso se situar: quem sou eu em relação ao conjunto? Qual função eu tenho? Que relação mantenho com a instituição? (COULON, 2008, p. 146)

\section{A SEMANA DE ACOLHIMENTO: RECEPÇÃO CALOUROSA DA UFSB}

A entrada na universidade é, na maioria das culturas, comemorada como uma conquista familiar. A possibilidade de fazer um curso universitário aponta para um futuro, tido como quase certo, de inserção no mercado de trabalho e mobilidade social, em especial para as famílias mais pobres.

É também encarada como rito de passagem para a vida adulta e, o conjunto de mudanças no formato e nas cobranças de aprendizagem, exige do aluno um amadurecimento e uma profissionalização do seu "ofício de estudante".

Considerando isto, é importante que as universidades encarem este momento com a importância devida, produzindo um acolhimento que fortaleça nos alunos, e em suas famílias, a sensação de conquista decisiva, mas que deve ser acompanhada de uma nova postura e de novas responsabilidades, com a universidade e com o grupo em que estará inserido.

Em maio de 2015 a UFSB, através de sua Pró-Reitoria de Sustentabilidade e Integração Social (PROSIS), identificou a necessidade de construir um evento de acolhimento que fosse ao mesmo tempo um rito solene, ainda ligado a tradições universitárias que merecem ser mantidas, e um ato de integração e festa, que criasse no estudante o sentimento de pertença necessário para a quebra do estranhamento e para a produção da afiliação à universidade.

Este evento foi denominado "Semana de Acolhimento: Recepção Calourosa", estabelecida após longo diálogo no âmbito da comissão organizadora composta por diversos grupos da universidade. A expressão "Semana de Acolhimento" constantemente reproduzida em email's, falas e na própria portaria que nomeou a comissão, foi incorporada à proposta original, deixando claro, aos poucos, que a expectativa do corpo de docentes, técnicos e estudantes envolvidos era de que este momento possibilitasse aos novos estudantes uma sensação de alegre acolhida, de felicidade institucional pela chegada dos novos alunos, parte importante do sucesso de uma universidade.

A expressão "Calourosa" foi recuperada de uma tradição da nossa universidade tutora", a UFBA, que a cerca de dez anos atrás, realizou um evento com este nome que não se limitava a um dia, ou a uma Aula Inaugural. Este evento articulava um conjunto de atividades de caráter institucional, orientador, cultural e festivo, que contou com participação expressiva criando uma nova cultura, colaborando inclusive com a redução de atos de trote.

${ }^{5}$ A tutoria da UFSB pela UFBA foi realizada entre 2013 e 2015.

\begin{tabular}{l|l|l|l|l|l} 
Rev. Inter. Educ. Sup. & Campinas, SP & v.3 & n.2 & 291-307 & maio/ago. 2017
\end{tabular}


A articulação entre as expressões "Calouro" e "Calorosa" foi muito acertada, e facilmente identificada com elementos culturais do nosso estado (ainda que carregado de estereótipos), que cumprem importante papel ao reforçar a intensidade e a alegria do corpo constituído em receber novos membros.

A denominação "Calouro" para designar o novo estudante universitário é também uma marca presente no estado da Bahia a tempos, e sempre foi marcado por representações mais positivas do que negativas, diferente dos termos "bixo" ou "fera" presentes em outras universidades.

A expressão "Somos a UFSB", ou "Somos todos a UFSB" que ganhou corpo especialmente entre os estudantes no III ENABLI - Encontro Nacional dos Bacharelados e Licenciaturas Interdisciplinares $^{6}$, passou a ser reproduzida, por meio de hashtags nas redes sociais, como instrumento de integração de calouros e veteranos da universidade.

A Semana de Acolhimento da UFSB foi realizada na semana anterior ao início das aulas, com o objetivo pragmático de antecipar a chegada dos novos alunos sem impactar o calendário e a carga horária das aulas. Além deste objetivo, ressaltamos o papel desta antecipação para a possibilidade de que os alunos chegassem ao primeiro dia de aula sem sentir o peso das dúvidas, angústias e até mesmo medo (de trote), comuns ao primeiro dia. A participação de calouros, mesmo ocorrendo uma semana antes do início oficial das aulas, foi significativo, o que impactou também numa melhor frequência durante a primeira semana de aulas, período onde a frequência costuma ser menor, inclusive entre os calouros.

O início da "Recepção Calourosa" ocorreu com um conjunto de atividades pensadas para possibilitar ao novo estudante e aos seus familiares a sensação de acolhimento de todo o corpo acadêmico constituído. Isso foi possível através das seguintes atividades:

- Palestra do Reitor sobre o modelo pedagógico realizada de maneira simultânea para os três campi;

- Atividade de Orientação Acadêmica realizada pela dupla de orientadores acadêmicos (docentes), responsáveis pelo acompanhamento e orientação destes estudantes durante seu processo de afiliação;

- Reunião com mães e pais realizada pelo decano do IHAC (primeiro elemento de contato institucional com o novo aluno), com a participação do setor de políticas de permanência da universidade, apresentando aos pais o conjunto de ações e programas voltados à melhor adaptação destes alunos à universidade;

- Encontro com as lideranças estudantis constituídas, com destaque para a representação discente no Conselho Superior Universitário, visando uma orientação dos próprios pares, sem a sensação de risco, típica das práticas de trote.

${ }^{6}$ O III ENABLI - Encontro Nacional dos Bacharelados e Licenciaturas Interdisciplinares, foi realizado entre 13 e 15 de novembro de 2015, no campus Sosígenes Costa (Porto Seguro/BA) da UFSB. 
Entre as atividades realizadas, a abertura da AOA, com significativa participação (de discentes e dos seus orientadores docentes), contribuiu no estabelecimento de um laço inicial entre os novos alunos e seus orientadores, com parte destes apresentando planejamento quadrimestral para as atividades de orientação acadêmica. Foi também debatido a Carta de Fundação e o Código de Ética Estudantil da UFSB. Ao final foi feita a assinatura do Termo de Compromisso Coletivo e do Termo de Compromisso Individual, documento institucional que estabelece uma espécie de contrato pedagógico entre o estudante, o grupo e a universidade.

Mecanismos acadêmicos de orientação ou tutoria têm sido cada vez mais adotados, com formatos diversos, pelas universidades. $\mathrm{O}$ potencial acadêmico e ao mesmo tempo integrador deste mecanismo é cada vez mais pesquisado, em especial acerca de sua influência na adaptação aos mecanismos formais e não formais de funcionamento da Universidade.

De modo semelhante, a afiliação institucional é considerada bem-sucedida quando o estudante consegue interpretar, usar e jogar com as regras da instituição, descobrir aquelas que estão escondidas e utilizá-las na construção individualizada de seu percurso. (SAMPAIO; SANTOS, 2012)

Como já comentado anteriormente, uma das motivações para a realização deste evento estava relacionada à consolidação do princípio de combate veemente a todo tipo de trote, já claro nas normas internas, mas que ainda necessitava de consolidação e legitimação entre o corpo discente.

Para que este objetivo se cumprisse foram adotadas as seguintes estratégias:

- Incorporar na comissão organizadora a quase totalidade da representação discente no CONSUNI (único corpo legítimo de representação dos estudantes até aquele momento);

- A negativa clara em legitimar atividades de "calourada" fora da universidade, em especial festas, ou atos afins;

- A celeridade do encaminhamento ao CONSUNI de uma denúncia de assédio entre estudantes, como forma de fortalecer e dar visibilidade ao papel do Código de Ética Estudantil;

- A valorização do ato de posse da CODE e da COES na principal cerimônia do evento (Aula Inaugural);

- A campanha contra a violência na universidade elaborada pela Coordenação de Acesso e Permanência Estudantil da UFSB e divulgada nas redes sociais durante todo o evento.

Portanto, associado a formatos e objetivos mais comuns nestes eventos (apresentação institucional, aula inaugural, etc.), a "Semana de Acolhimento - Recepção Calourosa" da 
UFSB se apresentou como uma oportunidade de experimentação de novos mecanismos de integração social e de adequação as novas condições impostas pela expansão e pelo novo perfil do corpo discente. A atenção ao tema do Trote, fenômeno ainda preocupante no cotidiano da gestão universitária, e a constituição de um formato inovador para a Orientação Acadêmica são contribuições que consideramos interessante neste evento.

No quadro das transformações da universidade (onde o REUNI e as Ações Afirmativas cumpriram papel destacado), em curso no Brasil, a entrada de estudantes de origem popular (muitos destes trabalhadores-estudantes) oferece um panorama novo e instigante para o desenvolvimento de estudos que privilegiem a escuta acerca das circunstâncias que envolvem suas vidas como estudantes de uma universidade pública.

\begin{abstract}
A reforma tem por objetivo central responder positivamente às demandas sociais pela democratização radical da universidade, pondo fim a uma história de exclusão de grupos sociais e seus saberes de que a universidade tem sido protagonista ao longo do tempo e, portanto, desde muito antes da atual fase de globalização capitalista. (SANTOS; ALMEIDA-FILHO, 2008, p. 51)
\end{abstract}

Esse cenário exige a definição de novas políticas e medidas pedagógicas que resultem em suporte efetivo aos novos estudantes, em especial ao longo do primeiro ano letivo, onde ocorre o maior número de interrupções, experiências de fracasso e abandonos. (SAMPAIO, 2011)

\title{
CONCLUSÕES
}

A experiência vivida durante a realização desta atividade - que teve uma segunda edição com poucas modificações no ano de 2016 - foi bastante reveladora do quanto estamos diante de uma nova "condição de estudante". Não há mais como ignorar um significativo processo de apropriação deste "lugar" na universidade por jovens oriundos de realidades onde a formação universitária sequer se apresentava como algo alcançável. Estamos falando aqui de um conjunto de famílias que sequer sabiam da existência deste espaço, e das possibilidades de empoderamento e crescimento individual e coletivo geradas pela formação universitária.

A beleza desta realidade não pode inebriar a nossa atenção quanto aos desafios colocados às universidades. Permanência não pode mais ser apenas uma palavra solta ao vento. Esta demanda exige o estabelecimento de instrumentos materiais e estruturas de reflexão constantes, voltadas diuturnamente para a recepção e o acompanhamento destes novos estudantes.

A localização deste estudante em específico, herdeiro de uma tradição familiar onde o capital cultural universitário não existe, deve ser realizada logo após a seleção por meio do SISU. Um contato acolhedor por parte da universidade pode ser o divisor de águas entre matricular-

n.2


se ou não. Informações básicas sobre este processo (a matrícula) e a exposição dos meios de apoio e assistência estudantil, serão decisivos para que este estudante não desista da vaga conquistada.

É importante perceber o quanto a universidade necessita da entrada e permanência deste novo estudante, para sua renovação e democratização enquanto instituição. Destarte aqueles que iludidos por suas noções de mérito - acham que estudantes com este perfil são um estorvo à universidade, não faltam elementos que demonstram o quanto estas trajetórias colaboram para uma renovação da academia, no sentido de obrigá-la a produzir novas linguagens e novos diálogos com saberes populares que pouco transitavam na universidade, pelo simples fato de que seus filhos lá não estavam.

O recurso da Semana de Acolhimento associado a diversos outros mecanismos adotados por outras universidades, em especial as novas universidades baianas calejadas pela necessidade de lidar com este público, pode, de algum modo, colaborar para o combate a ociosidade de vagas e a evasão escolar, e mais além, induzir uma autorreflexão sobre os objetivos e modelos de produção do conhecimento universitário.

\section{REFERÊNCIAS}

ALMEIDA FILHO, Naomar. Universidade Nova: Textos Críticos e Esperançosos. Brasília: Editora UnB / EDUFBA, 2007.

ALMEIDA FILHO, Naomar; JANINE RIBEIRO, Renato; MELLO, Alex Fiúza de. Por uma Universidade socialmente relevante. 2001. Disponível em:

<http://portal.mec.gov.br/dmdocuments/cne_alexfiuza.pdf $>$. Acesso em: 29 jun. 2017.

ALMEIDA-FILHO, Naomar. Universidade Nova: Textos Críticos e Esperançosos. Brasília: Editora UnB / EDUFBA, 2007.

BRASIL. Decreto-lei no 7.824, de 11 de outubro de 2012.

BRASIL. Lei de Cotas nº 12.711, de 29 de Agosto 2012.

BRASIL. Ministério da Educação. Portaria Normativa nº 18, de 11 de outubro de 2012.

COULON, Alain. A Condição de Estudante: a entrada na vida universitária. Salvador: EDUFBA, 2008.

INSTITUTO NACIONAL DE ESTUDOS E PESQUISAS EDUCACIONAIS ANÍSIO TEIXEIRA. Sinopse Estatística da Educação Superior 2015. Brasília, Inep, 2016. Disponível em: < http://portal.inep.gov.br/web/guest/sinopses-estatisticas-da-educacao-superior>. Acesso em: 29 jun. 2017. 
Manual da Atividade de Orientação Acadêmica - AOA - PROSIS-UFSB, 2014.

MOEHLECKE, Sabrina. Ações afirmativas: história e debates no Brasil. Cadernos de Pesquisa, n.117, nov. 2002.

NASCIMENTO, Tânia Lúcia Nunes do. Bullying: a realidade dolorida de um fenômeno sem distinção de gêneros. Revista Em Aberto - INEP, Brasília, v. 27, n. 92, p. 89-98, jul./dez. 2014.

UNIVERISDADE FEDERAL DO SUL DA BAHIA. Plano Orientador da Universidade Federal do Sul da Bahia. Itabuna: UFSB, 2014. Disponível em: $\langle$ http://ufsb.edu.br/wpcontent/uploads/2015/05/Plano-Orientador-UFSB-Final1.pdf>. Acesso em: 29 jun. 2017.

SAMPAIO, Sônia Maria Rocha (Org.). Observatório da Vida Estudantil. Primeiros Estudos. Salvador: EDUFBA, 2011.

SAMPAIO, Sônia Maria Rocha; SANTOS, Georgina Gonçalves dos. O conceito de afiliação como ferramenta para gestão pedagógica da educação superior. In: CONFERÊNCIA DA ASSOCIAÇÃO FORGES - FÓRUM DA GESTÃO DO ENSINO SUPERIOR NOS PAÍSES E REGIÕES DE LÍNGUA PORTUGUESA, 2. Macau, 2012. Anais... Macau: [s.n.], 2012.

SANTOS, Boaventura de Sousa; ALMEIDA-FILHO, Naomar. A Universidade no século XXI: Para uma Universidade Nova. Coimbra: Almedina; out. 2008.

SIQUEIRA, Vera Helena Ferraz de; ROCHA, Glória Walkyria de Fátima. Gênero e relações de poder no trote universitário: implicações para a cidadania. Simpósio Temático $\mathrm{n}^{\circ} 5$ -

Fazendo Gênero 8, Florianópolis, 2008. Disponível em:

<http://www.fazendogenero.ufsc.br/8/sts/ST5/Siqueira-Rocha_05.pdf >. Acesso em: 29 jun. 2017.

VIEIRA SEGUNDO, Luiz Carlos Furquim. Trotes universitários: brincadeira ou bullying?. Âmbito Jurídico, Rio Grande, v.16,, n. 112, maio 2013.

\footnotetext{
${ }^{\mathrm{i}}$ Sobre os autores

Sandro Augusto Silva Ferreira

E-mail: sandrosf@gmail.com / ORCID: http://orcid.org/0000-0003-1494-7249

Universidade Federal do Sul da Bahia - Brasil

Doutorando do IHAC da Universidade Federal do Sul da Bahia [UFSB].
} 